\title{
Procesos de eclesiásticos liberales en la diócesis de Badajoz (1824-1825)
}

\author{
José SARMIENTo Pérez
}

Apenas restaurado el absolutismo, el 1 de octubre de 1823, comenzó la sistemática represión de todos aquellos que se habian mostrado partidarios o simplemente condescendientes con los liberales durante el trienio constitucional. En el ámbito eclesiástico, el origen de dicha represión fue la Real orden de 6 de febrero de 1824. Sus seis artículos iban dirigidos contra los eclesiásticos que hubieran pertenecido a asociaciones secretas de cualquier tipo, con el objeto de que los jueces ordinarios, junto con los eclesiásticos pudieran efectuar embargo de bienes y prebendas, iniciar los procesos pertinentes y proceder correccionalmente a la reclusión en monasterios, conventos, casas de congregaciones $u$ oratorios eclesiásticos.

Las muchas consultas que llegaron a la Real Cámara desde todas las diócesis españolas pidiendo aclaración sobre las medidas que habian de tomarse contra los clérigos liberales, hacen pensar en el forcejeo político de los primeros meses después de la restauración, o quizás también en el deseo de un sector del clero dirigente para no dejar impunes a los eclesiásticos que habían delinquido. El delito político surgía ahora, tanto en lo civil como en lo canónico, como algo verdaderamente nuevo '. En la diócesis pacense, si la Real orden de 6 de febrero sentó las bases legales para que se iniciara la reacción absolutista contra el clero liberal, el órgano ejecutor de la represión fue el tribunal diocesano de Badajoz. 128.

1 Higueruela, Leandro, El clero de Toledo desde 1820-1823, Madrid 1979, págs. $123-$ 
Dicho tribunal estuvo ubicado en el mismo obispado y utilizó como cárcel dos dependencias, una denominada "la carbonera" y otra una cochera, según se desprende del proceso incoado al presbítero Fernando Cortés ${ }^{2}$. La composición del tribunal en esta época fue la siguiente: el obispo don Mateo Delgado Moreno - consumado absolutista y gran impulsor para que de nuevo se restableciera la Inquisición - fue el presidente del mismo. A continuación le seguía en importancia, el vicario general, que era el juez eclesiástico nombrado y elegido por los prelados para que ejerciese sobre sus súbditos la jurisdicción ordinaria. En los años de 1824 y 1825 ostentó el cargo don Antonio Chaparro Adame. Don Diego del Corral Guisado, presbitero racionero medio de la catedral de Badajoz, ostentó el cargo de promotor fiscal. Este era el funcionario encargado de promover la averiguación y corrección de todos los abusos y delitos, y en general de todo lo que fuese en contra de los derechos de la iglesia. El tribunal contaba también con la presencia de dos jueces capitulares adjuntos, nombrados cada año por el deán del cabildo catedralicio. Para el año 1824, fueron nombrados por el deán don Francisco Romero de Castilla, el canónigo prior don Santos García de Málaga y el canónigo magistral don Fernando Bernaldez. Y por último, el notario alguacil mayor, sobre el que recayó la doble misión de dar fe de todo lo acontecido en los procesos conforme a las leyes y la de custodiar a los presos de la cárcel eclesiástica. Ejercieron este cargo durante estos años, en un principio don Juan Manuel Espino, al ser procesado don José Ramos, y posteriormente don José María Barrantes.

Entre las atribuciones del tribunal estaban las relacionadas con la resolución de cuestiones matrimoniales, con asuntos relativos a la fe e, incluso, en los años de 1824 y 1825 , asumirá sobre todo competencias de carácter politico, referidas al esclarecimiento de la conducta observada por algunos eclesiásticos de la diócesis de Badajoz durante el período revolucionario de 1820 a 1823.

El procedimiento seguido por el tribunal en las competencias de carácter político fue el siguiente: en principio solicitó información secreta de personas de confianza o adictas a la causa realista sobre los eclesiásticos de la diócesis sospechosos de liberales. A continuación, si se confirmaban las sospechas, se le procesaba judicialmente, mientras el reo permanecía recluido en un convento o en la cárcel eclesiástica. Durante este tiempo, el tribunal recibía las declaraciones y ratificaciones de testif. 141.

${ }^{2}$ Archivo Diocesano de Badajoz, Sección Badajoz. (A.D.B.), Badajoz, Leg. 7, núm. 57, 
gos por ambas partes, que después se estudiarian junto con los escritos enviados por los mismos acusados y abogados defensores, hasta llegar finalmente a la sentencia definitiva a la que era condenado el procesado.

A raíz de entrar en vigor la mencionada Real orden de 6 de febrero, el capitán general del ejército y provincia de Extremadura Conde de Castroterreño, ordenó el 10 de febrero de 1824 a don José de Mazarrosa -gobernador político y militar de la plaza de Badajoz-, que expulsase de la ciudad "a toda persona sospechosa de adicta al fatal sistema constitucional de cualquiera clase y condición que sea" ${ }^{3}$.

Como consecuencia de esta orden el nuevo provisor Antonio Chaparro Adame -que sustituyó el 10 de febrero a Blázquez Prieto-, emitió un auto el 13 de febrero de 1824, por el que mandaba que quedasen separados de sus destinos los prebendados y capellanes de coro de la catedral de Badajoz, el cura del sagrario y otros eclesiásticos pacenses. El número total de afectados por esta decisión fueron 24. A todos se les obligaba a salir de esta ciudad en el término preciso de tres dias, pasando en calidad de reclusos a distintos conventos de Extremadura ${ }^{4}$. De los 24 eclesiásticos expulsados, 16 pertenecian al cabildo catedralicio. De estos 16, cuatro tenian la categoría de dignidad: tres canónigos y un maestrescuela. $Y 11$ correspondian al grupo de tres beneficiados: nueve capellanes de coro y dos racioneros. También se encontraba entre los expulsados Pedro Hidalgo Chacón, cura del sagrario. Completaban la lista siete presbíteros, cuatro de ellos securalizados y un fraile lego.

Como dijimos anteriormente, el tribunal antes de comenzar la formación de causas, solicitó información reservada a eclesiásticos de confianza de las distintas poblaciones de la diócesis. En el Archivo Diocesano de Badajoz, hemos estudiado algunos de estos informes relativos a ciertos eclesiásticos de los pueblos de Salvatierra de los Barros, Santa Marta, Alconchel, Zafra, Villar del Rey, Solana de los Barros, Higuera la Real y La Morera. Entre las acusaciones que se desprenden de estos informes, se suelen repetir: el haber observado una conducta de lo más exaltada, haber promovido el partido de la rebelión, haber tenido alguna relación con las milicias nacionales o con alguna sociedad secreta... Por otro lado, las informaciones resultaron algunas veces contradictorias, poniendo de manifiesto que la honestidad y objetividad de las personas que elaboraron dichos escritos, dejarían mucho que desear.

${ }^{3}$ A.D.B., Badajoz, Leg. 5, núm. 66.

${ }^{4}$ A.D.B., Badajoz, Leg. 7, núm. 89, f. 10-11. 
Cuando el tribunal recibió las informaciones reservadas sobre los eclesiásticos calificados de liberales, comenzó a instruir los procesos pertinentes en los primeros meses del año 1824. Todos los procesos fueron incoados entre este año y 1825, aunque su resolución no llegó a algunos casos hasta después de haber transcurrido varios años.

En todos los procesos estudiados en el Archivo Diocesano de Badajoz, una parte considerable de los mismos corresponde a las declaraciones efectuadas por los testigos o por el mismo acusado. Los procesos comienzan con las declaraciones de los testigos presentados por el fiscal, que en el caso del presbitero Pablo Moro y Bueno llegaron a ser $28^{5}$. En este apartado, suelen coincidir un grupo de personas que son reiterativas en sus acusaciones. Un porcentaje elevado lo constituyen los miembros del clero realista y sobre todo catedralicio, seguido de militares, voluntarios realistas, empleados de la administración de rentas reales, etcétera. Por descontado que la conducta politica y religiosa de los mismos, estaba claramente orientada a la causa realista, reflejando por tanto en sus manifestaciones una gran aversión hacia los procesados inculpándoles de delitos que en la mayoria de las ocasiones no podían ni demostrar. En consecuencia en sus comparecencias son repetitivas afirmaciones como éstas: "sabe y le consta por notoriedad", "ha oído decir", "parece", "es público y notorio", etc. Sobre este particular, el presbitero procesado Juan Fernández de Solis manifestó en su defensa "los enormes vicios de que adolecen todos los testigos presentados por la parte fiscal en esta causa y que les hace inhábiles para que sus dichos merezcan fe en juicio". Para ello, realizó unas declaraciones sobre ciertos testigos que comparecieron reiteradamente en los procesos ${ }^{6}$, y que nos dan una idea sobre la verosimilitud y autenticidad que estas personas mostraron en sus confesiones, y las relaciones existentes entre distintos miembros del clero a la hora de firmar declaraciones o delatar a personas sospechosas de liberales, con el fin de conseguir cargos y honores.

Sobre las acusaciones que estos testigos imputan a los eclesiásticos procesados, se debe establecer como premisas: primero, que un porcentaje muy elevado de las mismas carecía de aportación documental para ratificar lo dicho ante el tribunal. Y segundo, la contrariedad que se apreciaba en muchas declaraciones, sobre todo en lo referente a las logias secretas de masones y comuneros, porque se dio la circunstancia de que a un mismo procesado se le designó como perteneciente a ambas socie-

S ADB, Badajoz, Leg. 7, núm. 100, f. 31.

${ }^{6}$ ADB, Badajoz, Leg. 4, núm. 54, f. 285-288. 
dades a la vez, ya que el concepto público que tuviera esa persona es lo que imperaba.

Los delitos de los que son acusados los precesados, se pueden agrupar en tres aspectos: políticos, que llevaban implícito todo los referente a la promulgación, expansión o participación en las ideas liberales establecidas en la Constitución de 1812; religiosos, relacionados con cualquier ataque a la religión o a la jerarquía eclesiástica; y por último manifestaciones que atentaban contra el Rey o su familia.

En concreto las acusaciones más usuales que aparecen en los procesos son las siguientes: suele coincidir en principio, la acusación de liberal exaltado, declarado abiertamente por el partido de la rebelión y promovedor de dicho sistema. La participación en las fiestas organizadas en Badajoz por el ayuntamiento constitucional, con motivo de haber jurado la Constitución Fernando $\mathrm{VII}^{7}$. También la asistencia a las asonadas públicas, el haber cantado el "Trágala", o haber lucido en el sombrero el lema "Constitución o muerte". La asistencia y proclamación de discursos en las Sociedades Patrióticas, creadas en Badajoz, Zafra y Alconchel - esta última no aparece citada en la obra Las Sociedades Patrióticas (1820-1823) de Alberto Gil Novales- ${ }^{8}$.

La de pertenecer a alguna logia secreta de masones o comuneros. Con respecto a la masonería, en las declaraciones de los testigos, salen a relucir distintas «tertulias" en Badajoz La "Botica de Alonso Zambrano" situada en la plazuela de la Virgen de la Soledad, que fue mandada vigilar por sospechosa por el capitán general Conde de Castroterreño ${ }^{9}$. Regía la logia como hermano venerable Fernando Millares, siendo sustituido posteriormente por el presbitero Manuel de Silva y Ayant ${ }^{10}$. Otros lugares de reunión fueron la "casa del comerciante Patrón", la del comerciante Llugat ${ }^{11}$, la botica de Isidro Romero, la casa de José Albarrán en la plaza de San Andrés ${ }^{12}$, o el molino de la ciudad inmediato a Puerta

7 El diario de los públicos regocijos con que el Ayuntamiento constitucional de Badajoz, cuerpos, gremios y personas particulares han celebrado el dia memorable 9 de julio de 1820, en el que el mayor de los monarcas D. Fernando VII, concedió a sus pueblos la constitución política de la Monarquía española.

${ }^{8} \mathrm{ADB}$, Badajoz, Leg. 5 , núm. 62 , f. 2.

${ }^{9}$ ADB, Badajoz, Leg. 7, núm. 100, f. 25.

10 PÉrez, Pedro, "El ambiente político de Badajoz 1820-1823", Revista de Estudios Extremeños, IX. Badajoz 1935, pág. 131-132.

$"$ ADB, Badajoz, Leg. 4, núm. 54, f. 150.

${ }_{12}$ ADB, Badajoz, Leg. 4, núm. 56, f. 33. 
de Palmas, el cual fue conocido como "molino de los negros" ${ }^{13}$, a las que asistian personas importantes e influyentes de la capital, como el entonces provisor Blázquez Prieto.

En lo que respecta a la comunería y según las declaraciones, los núcleos de población pertenecientes a las diócesis donde se encontraron localizadas algunas torres fueron: Badajoz -donde se han contabilizado seis centros comuneros: una casa fuerte y cinco torres-, Olivenza y San Vicente de Alcántara -torre demarcada con el número 7 , con $30 \mathrm{com}$ ponentes y cinco de ellos presbíteros-.

Igualmente todo lo relacionado con el general Arco-Agüero fue considerado como delito. Arco-Agüero fue nombrado capitán general de la provincia de Badajoz en mayo de 1821, hasta que el 13 de septiembre de 1821 murió a consecuencia de la caída de su caballo mientras cazaba. En los procesos varios eclesiásticos fueron acusados de haber participado en su entierro, así como en la proyección de un catafalco que se pretendia hacer en el convento de San Francisco - desalojados previamente sus religiosos por una primera exclaustración- en homenaje al héroe liberal.

El haber participado en la vida pública durante el trienio liberal. Por ello fueron acusados los presbiteros Manuel de Silva y Ayant por ser diputado a Cortes, Pedro Hidalgo Chacón por pertenecer a la Junta Municipal de Beneficencia, Fernando Cortés por el cargo de escribiente en la oficina de crédito público y por haber sido capellán de los milicianos voluntarios de Badajoz y de Madrid, etc. Y por último, hablar contra los misterios de la religión, la jerarquía eclesiástica, el cabildo catedralicio, la inquisición, o la persona del rey o su familia, fueron considerados también muy atentatorios para la causa realista.

Posteriormente declaraban los testigos presentados por la defensa 0 por el mismo acusado. Sus manifestaciones siempre fueron relacionados con la justificación de algunos aspectos concretos de los procesados. Por ejemplo, el presbítero capellán de coro Nicolás Rodríguez solicitó la información de tres testigos para que certificasen el estado de necesidad e indigencia en que se encontraban ${ }^{14}$. En otros autos, sin embargo, las declaraciones se limitaron a negar las acusaciones que se le habian imputado al reo. Por profesiones, se observa un mayor número de testigos

${ }^{13}$ ADB, Badajoz, Leg. 4, núm. 54, f. 27.

${ }_{14}$ ADB, Badajoz, Leg. 3, núm. 50, f. 47. 
fuera del estamento eclesiástico, militares sobre todo, algún regidor o alcalde e incluso mendigos que fueron recogidos en la Real Casa Hospicio de Badajoz.

$Y$, finalmente era el mismo acusado quien declaraba ante el tribunal en el apartado denominado en los procesos "confesión con cargos". Para ello, el reo contestaba a una gama variada y abundante de preguntas, que servirían para ver las cosas desde un punto de vista distinto al mostrado por los testigos que declararon en contra. Las preguntas por un lado fueron de carácter general, relacionadas con las acusaciones vistas anteriormente, y por otro lado específicas y relativas al esclarecimiento de circunstancias particulares de los acusados.

Mientras el tribunal recibia todas estas declaraciones, los eclesiásticos procesados permanecían recluídos en distintos conventos de Extremadura y en la cárcel eclesiástica del obispado. Allí permanecerán varios meses en principio, realizando ejercicios espirituales y asistiendo a las actividades que las diferentes congregaciones efectuaban diariamente. La situación se mantuvo hasta la publicación del Real indulto de $1 .^{\circ}$ de mayo de 1824 ya que es a raíz de esta amnistía, cuando el provisor de la diócesis empieza a recibir los primeros escritos relacionados con dichos eclesiásticos. Los escritos fueron remitidos, por los mismos acusados, por algún familiar o por los abogados en quienes delegan los procesados la defensa de sus intereses. Los abogados podían ser elegidos por el mismo acusado, o el tribunal podía asignar uno de oficio, cuando el estado de pobreza del reo era muy notorio, como ocurrió con el presbitero Fernando Cortés ${ }^{15}$. Según se desprende del proceso incoado a Juan Fernández de Solís, el número de letrados que habían quedado en Badajoz en estos años, era muy escaso ${ }^{16}$, por ello un mismo abogado se encargó de defender a varios eclesiásticos a la vez. Como consecuencia, son familiares en los procesos los nombres de los juristas Román Tomás Henriquez, Pedro Alcántara Valcarcel, Toribio Benavente y Moraes o Vicente Durán Escobar.

Los objetivos fundamentales a los que fueron encaminados los procedimientos de la defensa, fueron: primero, lograr que los procesados fueran incluidos en el derecho de amnistía de $1 .^{\circ}$ de mayo de $1824^{17}$, y

15 ADB., Badajoz, Leg. 4, núm. 57, t. 50.

${ }^{16}$ ADB, Badajoz, Leg. 4, núm. 54, t. 69.

17 Decretos del Rey nuestro Señor D. Fernando VII y reales órdenes, resoluciones y reglamentos generales expedidos por la secretaría del despacho universal y consejos de S.M., por NIEVA, Josef María, VIII. Madrid, Imprenta Real, 1824, pág. 260. 
segundo, conseguir que no se reanudaran de nuevo los procesos, que posteriormente el provisor Antonio Chaparro puso en marcha amparándose en el Real decreto de 8 de octubre de $1824^{18}$.

El decreto de amnistía tuvo una gran repercusión en el clero procesado de la diócesis. La mayoría de estos eclesiásticos hicieron peticiones al tribunal para ser incluidos en la Real gracia de indulto. Tan solo en un principio hubo dos excepciones en la norma. Por un lado, el canónigo de la catedral Blas García Moreno -educado de niño en el Real palacio, al lado del obispo de Osuna y confesor de Carlos III- ${ }^{19}$. Y por otro, el capellán de coro de la catedral de Badajoz Nicolás Rodríguez ${ }^{20}$. Aunque posteriormente también serán incluidos en dicho decreto.

Todas las peticiones fueron unánimes en solicitar que concluyeran cuanto antes las reclusiones que padecian para que de esta forma pudieran reintegrarse de nuevo a sus domicilios particulares. En los mismos escritos, se ofrecen igualmente datos complementarios sobre las situaciones concretas que estaban sufriendo estos eclesiásticos, como por ejemplo, el tiempo de reclusión que llevaban hasta ese momento, que suele oscilar entre tres y cinco meses, los perjuicios e inconvenientes que venían padeciendo por ello (separación de sus cargos y familias, el no haber recibido noticia alguna del por qué de su procesamiento durante todo ese tiempo, o la lentitud en la resolución de sus causas), así como las motivaciones -enfermedad, estado de necesidad e indigencia, o perjuicios en negocios particulares- que exponian para que les fuera favorable la resolución de sus demandas.

El primer objetivo propuesto fue conseguido completamente ya que todos los procesados, al no estar comprendidos en ninguna de las quince excepciones del artículo segundo del mencionado decreto, fueron incluidos en el indulto. Alegando además el fiscal que con el tiempo que llevaban de reclusión, con los ejercicios espirituales realizados y con la condenación de las costas que producen estas diligencias, quedan suficientemente castigadas las faltas. Como consecuencia de ello, se otorgaron las respectivas licencias para volver a sus casas, alzándoles la reclusión que padecian. El ser incluido en la amnistía llevó aparejado el que todas las causas se archivasen, pero a la vez permaneciendo abiertas por si los clérigos juzgados volvian a reincidir en la mismas penas.

Pero si este primer objetivo se logró satisfactoriamente, será en la consecución del segundo cuando afloren abiertamente los enfrentamien-

\footnotetext{
${ }^{18}$ Decretos del Rey nuestro Señor..., IX, o.c. 222-224.

19 ADB, Badajoz, Leg. 3, núm. 49 a, f. 9 v.

20 ADB, Badajoz, Leg. 3, núm. 50, f. 27.
} 
tos de los acusados con el provisor Antonio Chaparro. Éste, basándose en la Real orden de 8 de octubre, ordenó que continuasen los procesos, ya que el indulto sólo fue extensivo a las penas civiles y pecuniarias, quedando por lo tanto expeditos los jueces para imponer las penas canónicas correspondientes. $Y$ empiezan de nuevo las reclusiones en la cárcel eclesiástica, casa de ordenandos y conventos, asi como la suspensión de licencias para celebrar misas, destitución de servicios y capellanías, etc. Esto motivó una gran oposición contra el provisor, por parte del clero procesado, patente en los numerosos escritos que los abogados le enviaron criticando tal medida, y, en algún caso, en la deserción y huida al vecino reino de Portugal.

La reacción general de los procesados, fue la de dirigir sus peticiones al Tribunal Superior Metropolitano de Salamanca de la Provincia de Santiago, para que actuase en consecuencia. Los jueces metropolitanos -D. Miguel Sandalio y Salgado, y D. Ramón Artesero-, establecieron un plazo de quince dias para recibir el auto original del proceso y la presencia del abogado para estudiar los informes y emitir la sentencia correspondiente.

Sin embargo, los procesos continuaron su curso hasta que el Tribunal diocesano dictaminó la sentencia definitiva. En la resolución de estas sentencias, jugó un papel destacado el promotor fiscal diocesano D. Diego del Corral Guisado. Éste estudió los casos particulares de los procesados, las acusaciones que los testigos les imputaban y sobre todo la defensa efectuada por los abogados, y con toda esta información realizó una serie de dictámenes dirigidos al tribunal con el objeto de que las penas que él solicitaba fuesen consideradas y ejecutadas por él mismo. Las consideraciones de las que parte son claramente realistas y siempre relacionadas con los principios liberales, que atentaban según su punto de vista a la causa del Altar y del Trono ${ }^{21}$. En líneas generales las penas sugeridas por el promotor fiscal, tanto al tribunal diocesano como al metropolitano de Salamanca, solian ser más severas que las impuestas definitivamente por los jueces. Sin embargo, éstas fueron acatadas en algunos casos o modificadas en otros por el juez eclesiástico a la hora de emitir la sentencia definitiva. El $72 \%$ aproximadamente de las sentencias dictaminadas -en los procesos estudiados - por el tribunal diocesano de Badajoz se firmaron en el año 1825 entre los meses de marzo y octubre, y el $28 \%$ restante en los años de 1826, 1827 e incluso en 1830.

${ }^{21}$ ADB, Badajoz, Leg. 5 , núm. 68, f. 1. 
El conjunto de sentencias las podemos agrupar en los siguientes apartados: un $23 \%$ inciden en la privación a los procesados de las licencias de celebrar, predicar y confesar por un espacio de tiempo que osciló entre los seis meses y dos años. Para obtener de nuevo las licencias por parte del obispo, tenian que conseguir la dispensa de la irregularidad y la retractación pública de sus errores.

En un $17 \%$-salvo por pobreza notoria del reo- se condena a los procesados a la liquidación de todas las costas originadas en la tramitación de los autos. Se comienza con el provisor - por los derechos y providencias dictadas en las causas-, seguido del promotor fiscal - por los escritos efectuados-, del notario alguacil mayor -por sus notificaciones-, de los oficios practicados por el tribunal, y por último de los pliegos de papel utilizados, incluyendo el aumento perteneciente a la Real Hacienda.

Aunque los procesados ya habian sufrido reclusión, sin embargo, un $16 \%$ de las sentencias vuelven a incidir en este mismo aspecto. El tiempo que debian permanecer recluídos en el convento o monasterio destinado, osciló entre los dos y ocho años. La máxima pena —ocho añosse le aplicó al doctoral D. Pedro Mendo. Durante todo ese tiempo los eclesiásticos debian ser instruidos en las obligaciones de su ministerio, especialmente en la sumisión, respeto y obediencia al Rey, y cumplir las actividades diarias que practicasen dichas congregaciones. Los conventos a los que fueron destinados dichos eclesiásticos pertenecian en la mayoría de los casos a la diócesis de Badajoz, pero también fueron enviados a otros situados fuera de esta jurisdicción eclesiástica, entre los que destacamos, el convento de capuchinos de Marchena, el monasterio de la Cartuja de Sevilla y la casa oratorio de San Felipe Neri de la misma capital.

Un $12 \%$ de las sentencias inciden en la privación de beneficios, prebendas o capellanías que tenían u ocupaban los procesados. Un $10 \%$ de las mismas declaran al reo incluido en la irregularidad de delito, bien por rebelarse contra su legítimo soberano Fernando VII, o bien por haber celebrado el santo sacrificio de la misa después de haberse inscrito en alguna sociedad secreta de masones o comuneros.

Un $8 \%$ inciden en las licencias que se les dieron a algunos clérigos, expulsados de los lugares donde ejercían su ministerio, para fijar su domicilio en su pueblo natal o en cualquier otro pueblo del obispado, pero siempre bajo la vigilancia atenta del párroco de la villa donde se estableciese. El $6 \%$ se refiere a la obligación de realizar ejercicios espirituales 
durante varios días. El secuestro de rentas recayó en un $4 \%$ de las sentencias. Igualmente otro $4 \%$ hace referencia al sobreseimiento y archivo de las causas correspondientes, pero siempre condicionado por la reclusión que anteriormente habian padecido estos eclesiásticos.

Las sentencias definitivas emanadas del tribunal diocesano de Badajoz fueron posteriormente confirmadas o modificadas por el tribunal metropolitano de Salamanca. Sin embargo, con el correr del tiempo, estas sentencias se alterarán completamente. Según los escritos recogidos al final de cada proceso, observamos que es a raíz del año 1830, y con D. José Luis de Lima como nuevo provisor del obispado, cuando se empieza con el sobreseimiento de las causas y la absolución de las penas impuestas anteriormente a los procesados.

En conclusión, basándonos en los procesos estudiados, podemos afirmar que el foco del liberalismo durante el trienio constitucional, en lo que respecta al clero diocesano, se encontró circunscrito en Badajoz, y principalmente en el cabildo catedralicio. Igualmente, la participación de un sector del clero liberal en la vida pública de la diócesis durante esos años, fue generalmente muy activa.

Fue a raíz de la Real orden de 6 de febrero de 1824, cuando el tribunal diocesano de Badajoz comenzó la represión contra los clérigos que se habian mostrado partidarios del liberalismo. En líneas generales podemos estimar que un $20 \%$ aproximadamente del clero secular del obispado de Badajoz fue procesado entre los años 1824 y 1825 por la conducta política y religiosa observada durante el trienio liberal. Mientras que el número de procesamientos a miembros del clero regular masculino fue muy inferior, estimamos tan sólo un $2 \%$. Este hecho nos pone de relieve que el sentimiento liberal fue abrazado por una importante facción eclesiástica a lo largo del tiempo del constitucionalismo ${ }^{22}$. Adhesión no sólo limitada al clero secular de la capital, sino arraigado también en parte del clero secular rural y minoritario en las órdenes religiosas masculinas ${ }^{23}$.

Por otro lado debe de considerarse la represión conservadora como

22 Cuenca ToRibio, José Manuel, Procesos de curas liberales en el Medina Sidonia (Cádiz) de 1825. Hispania Sacra, 1973. 80.

${ }^{23}$ Revuelta GonzALEz, Manuel, La exclaustración (1833-1840). Madrid, BAC, 1976, pág. 
una reacción a la que los liberales llevaron a cabo durante el trienio ${ }^{24}$. Prueba de ello en la diócesis pacense fue la expulsión de varios eclesiásticos realistas, entre los que se encontró el provisor Antonio Chaparro Adame, a consecuencia del Real decreto del Gobierno constitucional de $1 .^{\circ}$ de octubre de $1822^{25}$ y el cumplimiento de la Real orden de 21 de enero de 1823 sobre la suspensión de licencias y traslación de residencia de varios eclesiásticos seculares y regulares de la diócesis de Badajoz ${ }^{26}$.

24 Esta tendencia es la mantenida por: MARTíneZ DE VELASCO, Ángel, “Estudio del clero toledano a través del concurso parroquial de 1825", Hispania Sacra, XXV, 1972, págs. 453463; Higueruela, Leandro, El clero de Toledo desde 1800-1823. Madrid, 1979. CANDEL Crespo, Francisco, Clero liberal y absolutista en la Murcia de Fernando VII. San Javier, 1978, págs. 48-49.

${ }_{25}$ ADB, Badajoz, Leg. 7, núm. 93.

26 ADB, Badajoz, Leg. 2, núm. 98. 